
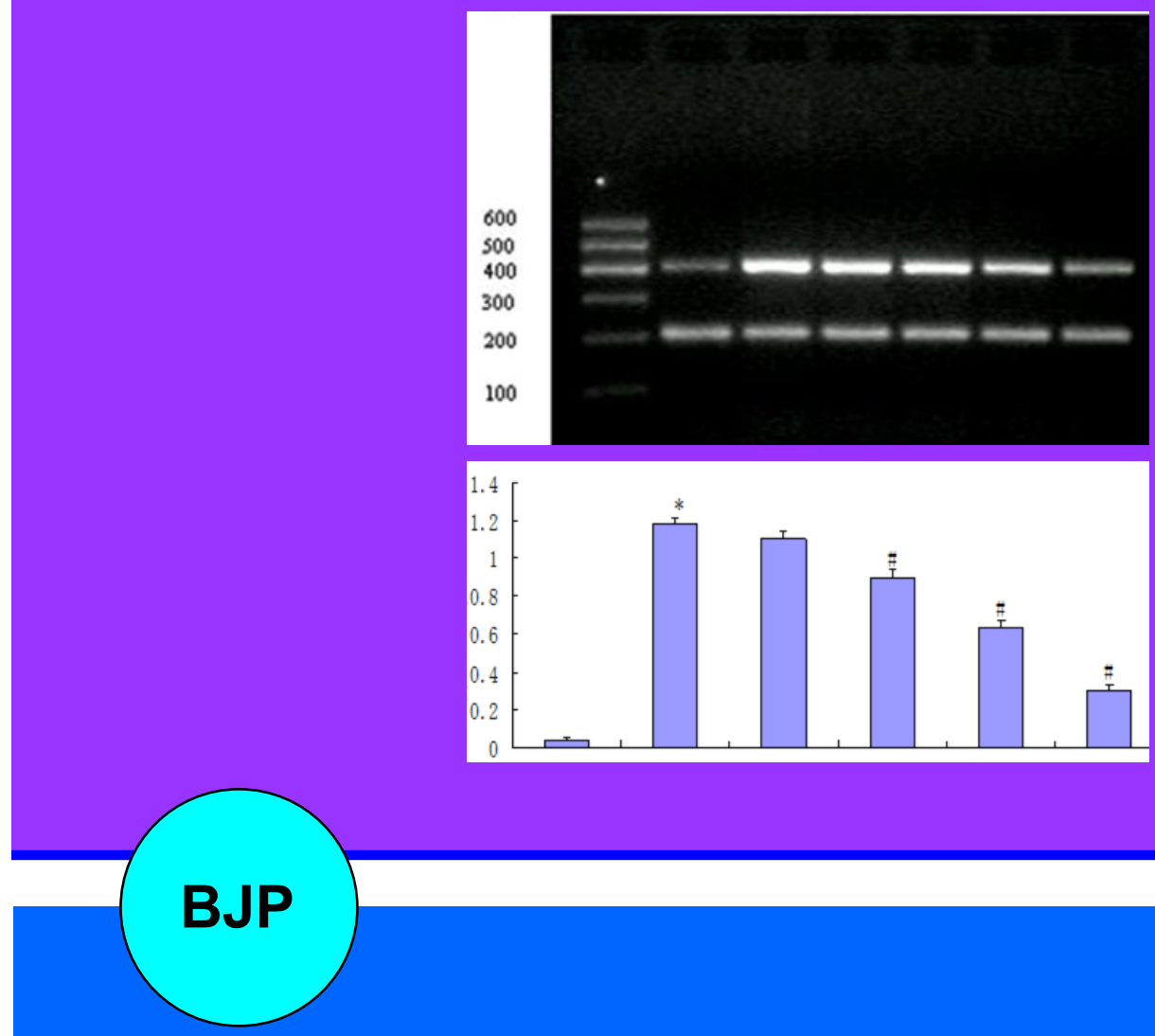

Bangladesh Journal of Pharmacology

Research Article

Effects of Paeonolon proliferation and collagen synthesis of rat cardiac fibroblasts induced by aldosterone 


\title{
Effects of paeonol on proliferation and collagen synthesis of rat cardiac fibroblasts induced by aldosterone
}

\author{
Qian Xu, Li-Na Wang, Jing-Yi Zhao, Yan-Hong Xiao and Chao Du
}

Department of Biochemistry, Chengde Medical University, Chengde 067000, Hebei, China.

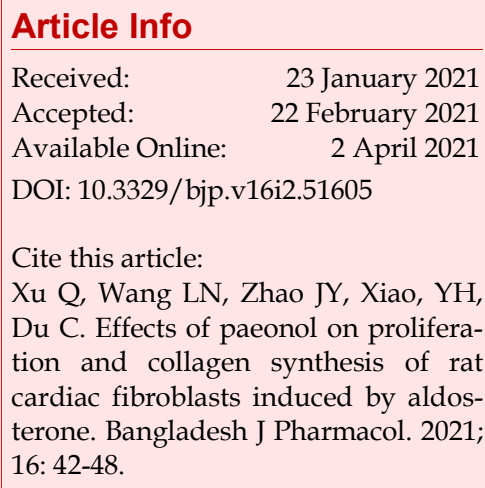

\section{Abstract}

The aim of this study was to explore the possible molecular mechanisms of paeonol in preventing ventricular remodeling. The cell viability of neonatal rat cardiac fibroblasts was detected by the method of MTT. RT-PCR and Western blot were used to measure the expression of TGF- $\beta 1$, type I collagen and type III collagen. After treating the cardiac fibroblasts with paeonol, the cell viability decreased $(\mathrm{p}<0.01)$, and the expression of TGF- $\beta 1$, type I collagen and types III collagen was significantly reduced $(p<0.01)$. Thus, paeonol can inhibit the proliferation of fibroblast cells induced by aldosterone. The molecular mechanism is related to the down-regulation of TGF- $\beta_{1}$ and type I and III collagen gene expression.

\section{Introduction}

After myocardial infarction, ventricular remodeling will occur in the infarcted area, leading to a severe decline in cardiac function and eventual heart failure (Toldo et al., 2015; Lee et al., 2016; Lagarto et al., 2019). Therefore, delaying or preventing the occurrence and development of ventricular remodeling is critical to the prevention and treatment of heart failure after myocardial infarction (Shintani et al., 2017). The mechanism of ventricular remodeling is very complex and characterized by extracellular matrix accumulation and fibrosis (Gao et al., 2017; Chen et al., 2020). The sympathetic nervous system is first activated after acute myocardial infarction (Sunaga et al., 2019), followed by the reninangiotensin system, and the activation of it will lead to increased synthesis and releasing of aldosterone. (Lieu et al., 2014; Han et al., 2020). The increase in aldosterone in the early stage can increase cardiac output, but the long-term results can cause sodium and water retention, electrolyte imbalance, and ultimately arrhythmia (Schmidt et al., 2010; Prins et al., 2019). On the other hand, myocardial and vascular interstitial collagen deposition and fibrosis can lead to an increase in ventricular wall stiffness, the decrease of ventricular compliance, and the damage to diastolic function.

It induces myocardial fibrosis, resulting in impairment of myocardial pump function, which is one of the critical effects of aldosterone on the heart (Dartsch et al., 2013). Collagen is an independent factor of myocardial fiber necrosis, and aldosterone can directly induce its synthesis. At the same time, aldosterone can break the balance of matrix collagen synthesis and degradation, thereby promoting the accumulation and fibrosis of extracellular matrix (Hayashi et al., 2003). Aldosterone can also induce myocardial fibrosis by up-regulating the level of angiotensin type I receptor; activating macrophages to increase the production of transforming growth factor $\beta_{1}$ (TGF- $\left.\beta_{1}\right)$, and the role of TGF- $\beta_{1}$ is to stimulate cardiac fibroblasts to synthesize collagen and promote myocardial fibrosis (Tsutamoto et al., 2001; Hayashi et al., 2001; Lu et al., 2019).

In recent years, it has been reported in China that paeonol has a wide range of cardiovascular pharmacological effects (Zhao et al., 2014; Gu et al., 2015; Zhou et al., 2017): a) it can significantly reduce the content of 
malonaldehyde and the concentration of creatine kinase in myocardial ischemia tissue, increase the activity of superoxide dismutase, and increase the clearance rate of endogenous oxygen-free radicals; b) it can significantly antagonize the arrhythmic effect of myocardial ischemia-reperfusion model in rats by inhibiting calcium channels and reduce the myocardial ischemia and infarction range; c) cell experiments show that paeonol can inhibit the expression of MMP-9, IL-1 $\beta$, and IL-8 induced by TNF- $\alpha$, indicating that paeonol had an anti-inflammatory effect; d) paeonol can improve ventricular remodeling after myocardial infarction by blocking the inflammatory signal pathway in vivo. Previous studies have shown that paeonol has prominent antioxidant activity and a strong protective effect on myocardial ischemia-reperfusion injury. Paeonol can improve ventricular remodeling after myocardial infarction by inhibiting NF- $\mathrm{kB}$ inflammatory pathway, however, whether it can inhibit the reninangiotensin-aldosterone system and inhibit ventricular remodeling after myocardial infarction and its molecular mechanism need to be further studied.

In this study, neonatal rat cardiac fibroblasts were cultured in vitro. The cell model of fibroblast proliferation and collagen synthesis was established with aldosterone as the inducing factor, which was used as the cell model of ventricular remodeling. The proliferation level of cardiac fibroblasts was detected. The expression of TGF- $\beta_{1}$ mRNA and type I collagen mRNA were detected. The expression of type III collagen protein was measured. This study aimed to observe the effect of paeonol on ventricular remodeling after myocardial infarction at the cellular level by inhibiting the renin-angiotensin-aldosterone system and explore its molecular mechanism.

\section{Materials and Methods}

\section{Chemical and reagents}

DMEM medium was obtained from Gibco. Trypsin and aldosterone were obtained from Sigma. Paeonol injecttion was purchased from Ningbo Tianzhen company. Trizol was purchased from Invitrogen and RT-PCR kit from TaKaRa Biotechnology. All other chemicals used were of the purest grade commercially available.

\section{Cell culture}

The heart tissue of suckling mice was minced, and a trypsin digestion solution was added. It was stirred on a magnetic stirrer for $8 \mathrm{~min}$, and the calf serum was added to inactivate trypsin. This process could be repeated 8-10 times until the tissue is digested completely. Cells were washed with D-Hanks solution and centrifuged at $1,000 \mathrm{rpm}$ for $10 \mathrm{~min}$. This operation was repeated once. The cells were resuspended with DMEM medium containing $10 \%$ fetal bovine serum, seeded in culture flasks, and cultured in a $37^{\circ} \mathrm{C}, 5 \% \mathrm{CO}_{2}$ incubator for $90 \mathrm{~min}$. The culture flask was shaken gently to pour out the cardiomyocyte suspension that had not yet been attached. Then adherent fibroblasts were observed under a microscope. When the cell density was $80 \%$, it was digested and passaged with $0.08 \%$ trypsin- $0.01 \%$ EDTA mixed digestive juice. Cells at passages 2-4 were used for experiments.

\section{Experimental grouping}

The cardiac fibroblasts were divide into six groups randomly: normal control group, aldosterone $\left(10^{-7} \mathrm{~mol} /\right.$ L) model group, paeonol low-dose $\left(10^{-7} \mathrm{~mol} / \mathrm{L}\right.$ aldosterone $+25 \mathrm{mg} / \mathrm{L}$ paeonol), medium-dose group: (10-7 $\mathrm{mol} / \mathrm{L}$ aldosterone $+50 \mathrm{mg} / \mathrm{L}$ paeonol), high-dose group $\left(10^{-7} \mathrm{~mol} / \mathrm{L}\right.$ aldosterone $+100 \mathrm{mg} / \mathrm{L}$ paeonol $)$, captopril group $\left(10^{-7} \mathrm{~mol} / \mathrm{L}\right.$ aldosterone $+1 \mathrm{mg} / \mathrm{mL}$ captopril). The normal control group cells were maintained in DMEM supplemented with $5 \%$ fetal bovine serum.

RT-PCR to detect the expression of TGF- $\beta_{1}$ mRNA and type I collagen mRNA in cardiac fibroblasts of each group

Cardiac fibroblasts at passages 2-4 were used for subsequent RNA extraction. When the cells reach $80 \%$ confluency, trizol $(1 \mathrm{~mL})$ was added to each well, and pipetted the cells repeatedly until there were no visible cell clumps remained, and left at room temperature for 5 min. Chloroform $(0.2 \mathrm{~mL})$ was added, shaken vigorously for $15 \mathrm{sec}$ and incubated at room temperature for $5 \mathrm{~min}$. After centrifugation at $12,000 \mathrm{rpm}$ at $4^{\circ} \mathrm{C}$ for $15 \mathrm{~min}$, the upper layer was carefully transferred to a new Eppendorf tube. Moreover, an equal volume of isopropanol was added. After centrifugation at 12,000 rpm at $4^{\circ} \mathrm{C}$ for $10 \mathrm{~min}$, the supernatant was discarded, and the bottom deposit was total RNA.

An amount of $2 \mu \mathrm{g}$ RNA was reverse transcribed into complementary DNA (cDNA), and cDNA was amplified into DNA products. TGF- $\beta_{1}$ PCR amplification was performed with the following parameters: 30 cycles, $94^{\circ}$ $\mathrm{C}$ for $2 \mathrm{~min}, 94^{\circ} \mathrm{C}$ for $30 \mathrm{sec}$, annealing at $61.2^{\circ} \mathrm{C}$ for 30 sec, extension at $72^{\circ} \mathrm{C}$ for $50 \mathrm{sec}$. The annealing temperature of type I collagen was $58^{\circ} \mathrm{C}$. The annealing temperature of $\beta$-actin was $60.4^{\circ} \mathrm{C}$.

The primer sequences used for TGF- $\beta_{1}$ were: forward, $5^{\prime}$ -GCCTCCGCATCCCACCTT TG-3' and reverse, 5'-GCGGTTGACTTCTTTGGCGT -3' The length of the PCR type I collagen product was $396 \mathrm{bp}$. The primer sequences used for type I collagen was: forward, 5'-TGCCGTGACCTCAAGATGTG -3' and reverse, 5'CACAAGCGTGCTGTAGGTGA- 3'. The length of the PCR type I collagen product was $462 \mathrm{bp}$. The primer sequences used for $\beta$-actin were forward, 5'-CACCCGCGAGTACAACCTTC-3' , and reverse, 5'-CCCATACCCACCATCACACC-3'. The length of the PCR $\beta$-actin product was $207 \mathrm{bp}$. 


\section{Box 1: MTT Assay}

Principle

Quantification of cell viability and proliferation in vitro is assessed by the cell metabolic activity using a colorimetric method.

\section{Requirements}

Cultured cardiac fibroblasts, DMEM medium, Micro-plate reader, Formazan, MTT solution, 96-well plate

Procedure

Step 1: The second-generation cultured cardiac fibroblasts were cultured in 96-well plates at a density of $1 \times 10^{5}$ cells with $200 \mu \mathrm{L}$ medium.

Step 2: After cells reached $80 \%$ confluence, the culture medium was discarded.

PCR product $(5 \mu \mathrm{L})$ was entirely mixed with DNA loading buffer $(2 \mu \mathrm{L}$ of $6 \times)$ and separated by $2 \%$ agarose gel electrophoresis (constant voltage, 160V, $50 \mathrm{~min}$ ). The gels were visualized and photographed under a UV transilluminator. Quantity One software was applied for semi-quantitative analysis. The ratio of the optical density of the target band to that of $\beta$-actin was estimated as the relative level of mRNA expression of each target gene.

Western blot for detecting type III collagen protein expression in cardiac fibroblasts of each group

When the density of well-growing cardiac fibroblasts cells from passages two to four reached $80 \%, 150-200 \mu \mathrm{L}$ of the cell lysate was added, and the culture flask was shaken, and the cells were scraped off the cell culture flask after ice bath for $20 \mathrm{~min}$. The protein lysate was transferred to the EP tube, shook for $30 \mathrm{sec}$ each time, once per $5 \mathrm{~min}$, for a total of 8 to 10 times. Furthermore, the shock was carried out for $30 \mathrm{sec}$ each time, once per $5 \mathrm{~min}$, for a total of eight to ten times. Then centrifuged at $12,000 \mathrm{rpm}$ for $20 \mathrm{~min}$ at $4^{\circ} \mathrm{C}$. The supernatant was the protein extract.

Protein concentration was measured using the BCA method, SDS-PAGE electrophoresis, membrane transfer, and the addition of primary antibodies: (1:200 for type III collagen and 1:3000 for $\beta$-actin), and incubation for two hours at room temperature on a shaker. After washing with TBST, the secondary antibody was added: (the dilution ratio of type III collagen was 1:3000, the dilution ratio of $\beta$-actin was 1:5000) and incubated in a shaker at room temperature for one hour. After washing with TBST, the film was developed.

\section{Statistical analysis}

The experimental data were expressed as mean \pm SD. SPSS 17.0 software was used for statistical analysis. One -way analysis of variance was used to compare the means of measurement data among multiple groups,
Step 3: Furthermore, $200 \mu \mathrm{L}$ of DMEM medium was added to each well to synchronize the cells.

Step 4: At the end of the treatment period, $20 \mu \mathrm{L}$ of MTT solution $(5 \mathrm{mg} / \mathrm{mL})$ was added to each well.

Step 5: The cells were incubated at $37^{\circ} \mathrm{C}$ for 4 hours.

Step 6: The supernatant was removed with caution, and $150 \mu \mathrm{L}$ DMSO per well was added to dissolve the formazan product completely.

Step 7: The absorbance was detected at $490 \mathrm{~nm}$ with a microplate reader.

Reference

Xu et al., 2015

Reference (video)

Bahuguna et al., 2017; Wang et al., 2018

and SNK test was used for pairwise comparison. $\mathrm{p}<$ 0.05 was considered statistically significant.

\section{Results \\ Cell viability was evaluated by MTT}

The viability of cardiac fibroblasts in the model group (aldosterone group) was significantly increased $(\mathrm{p}<0.01)$. However, after adding different concentrations of paeonol, the cell viability of paeonol medium and high dose groups was significantly reduced $(p<0.01)$, and the cell viability of paeonol in the high dose group was almost indifferent from that of positive control captopril group (Figure 1).

\section{RT-PCR was used to detect TGF- $\beta 1$ mRNA expression} and type I collagen in cardiac fibroblasts of each group

Between the $300-400$ bp regions, a bright TGF- $\beta_{1}$ band was observed. Between the $400-500$ bp regions, a clear collagen I band was observed. Moreover, between the 200-300 bp regions, a clear $\beta$-actin band was observed (Figure 2A; Figure 3). RT-PCR results showed that after $10^{-7} \mathrm{~mol} / \mathrm{L}$ aldosterone was applied to cardiac fibroblasts for 24 hours, the expression of TGF- $\beta_{1}$ mRNA and type I collagen mRNA in the model group was significantly enhanced compared with the normal control group $(p<0.01)$. Compared with the model group, the expression of TGF- $\beta_{1}$ mRNA and type I collagen mRNA in the paeonol low-dose group was not significantly changed. However, TGF- $\beta_{1}$ mRNA and type I collagen mRNA expression in the middle-dose and the high-dose group of paeonol and the captopril group were remarkably lower than that of the model group $(\mathrm{p}<0.01)$ (Figure 2B; Figure 3B).

\section{Western blot was used to measure the expression of type III collagen in cardiac fibroblasts}

Western blot results showed that a type III collagen 


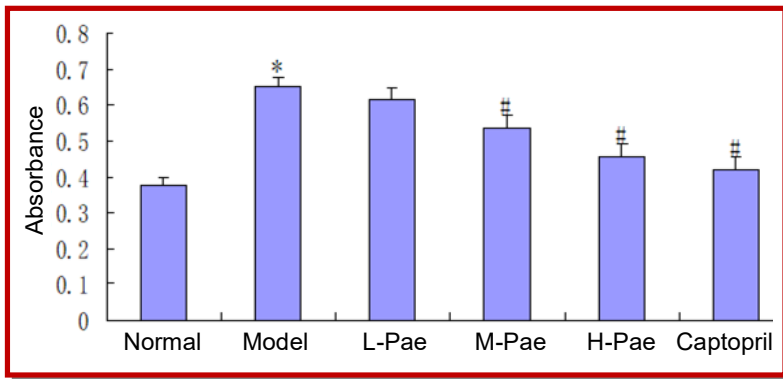

Figure 1: Cell viability was detected in cardiac fibroblasts in each group by the method of MTT. Compared with the normal control group ${ }^{*} p<0.01$; compared with the model group, ${ }^{\#} \mathrm{p}<0.01$

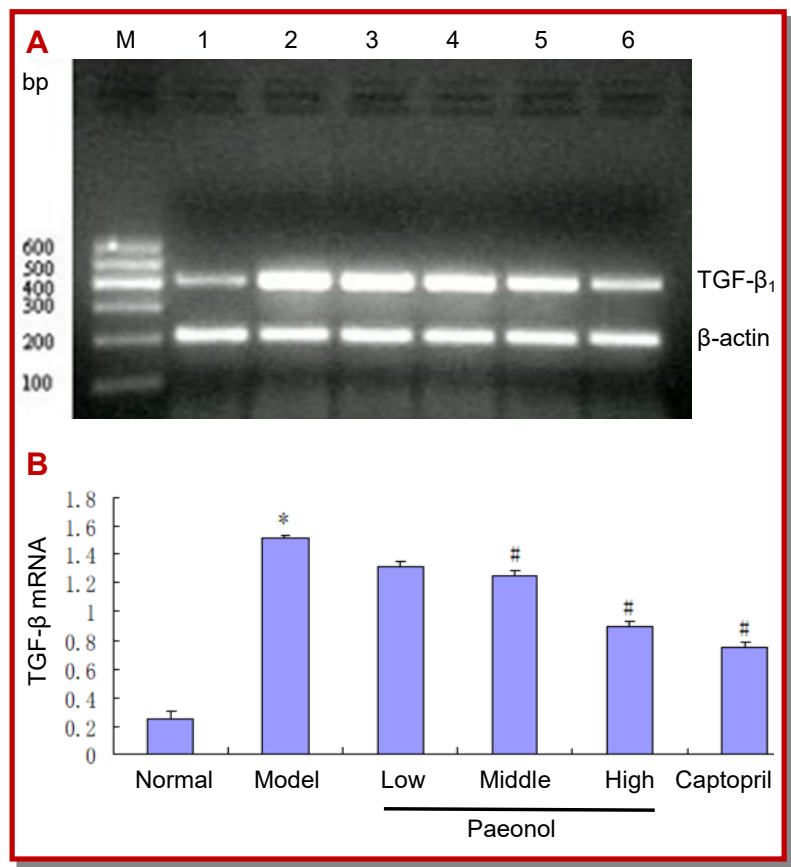

Figure 2: TGF- $\beta 1$ mRNA expression of cardiac fibroblasts in each group by RT-PCR. 1-the normal control group; 2-the aldosterone model group; 3-the low-dose group of paeonol; 4the middle-dose group of paeonol; 5-the high-dose group of paeonol; 6-the captopril group; M Marker (A); Compared with the normal control group, ${ }^{*} \mathrm{p}<0.01$; compared with the model group, ${ }^{\mathrm{p}}<0.01$ (B)

band was observed between protein Marker 72 KD-95 KD. Western blot results showed that a $\beta$-actin band could be seen between protein Marker 34 KD-55 KD (Figure 4A). Compared with the normal control group, the expression of type III collagen in the model group was significantly enhanced $(\mathrm{p}<0.01)$. Compared with the model group, the expression of type III collagen in each dose group of paeonol was enhanced $(p<0.01)$ in a dose-dependent manner with the increase of paeonol concentration. Compared with the low-dose group of paeonol, the expression of type III collagen was enhanced in the paeonol middle-dose group $(\mathrm{p}<0.01)$. Compared with the middle-dose group of paeonol, the expression of type III collagen was significantly

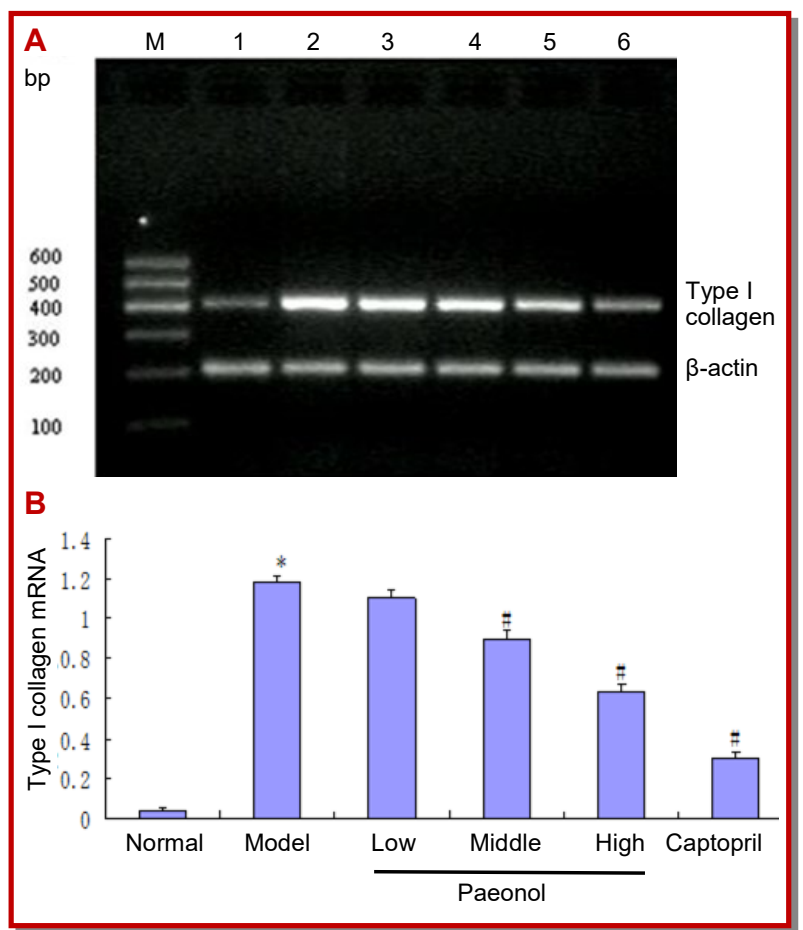

Figure 3: The type I collagen mRNA expression of cardiac fibroblasts in each group by RT-PCR. 1-the normal control group; 2-aldos-terone model group; 3-the low-dose group of paeonol; 4-middle-dose group of paeonol; 5-the high-dose group of paeonol; 6-the captopril group; M Marker (A); Compared with the normal control group, ${ }^{*} \mathrm{p}<0.01$; compared with the model group, ${ }^{\#} \mathrm{p}<0.01$ (B)

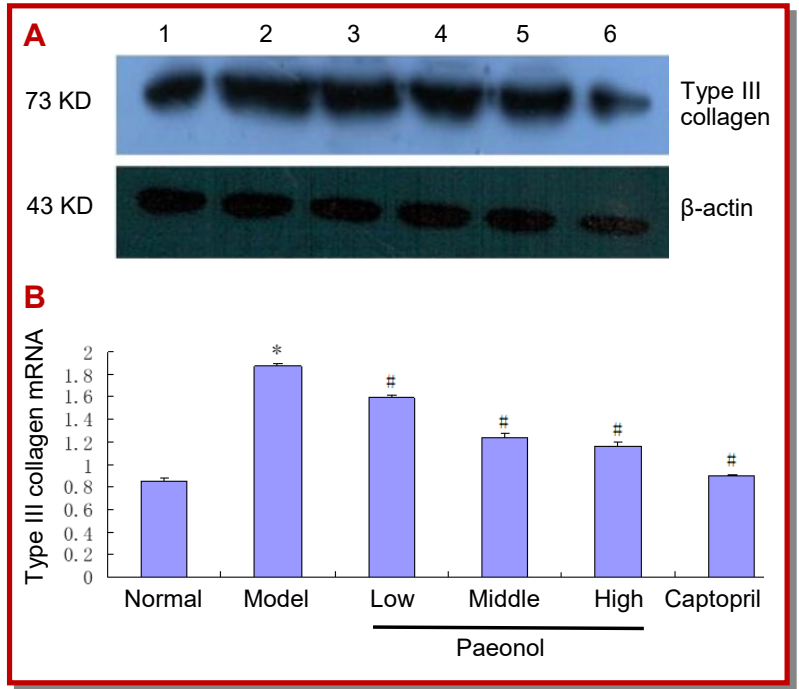

Figure 4: Type III collagen expression of cardiac fibroblasts in each group by Western blot. 1-the normal control group; 2-the aldosterone model group; 3-the low-dose group of paeonol; 4the middle-dose group of paeonol; 5-the high-dose group of paeonol; 6-the captopril group; $M$ Marker (A); Compared with the normal control group, ${ }^{*} \mathrm{p}<0.01$; compared with the model group, ${ }^{\#} \mathrm{p}<0.01$ (B)

enhanced in the high-dose group of paeonol $(\mathrm{p}<0.01)$. Compared with the model group, the protein 
expression of type III collagen was enhanced in the captopril group $(\mathrm{p}<0.01)$ (Figure 4$)$.

\section{Discussion}

As the primary effector cells of myocardial fibrosis, cardiac fibroblasts play an irreplaceable role in MF progression. Cardiac fibroblasts are the primary cells constituting the myocardial tissue, accounting for approximately more than $60 \%$ of the total number of cells. Cardiac fibroblasts are an essential component of the extracellular matrix, which can mediate various signaling transduction between cells and non-cellular tissues such as chemical and electrochemical signaling (Wang, 2013), and their proliferation, as well as increased synthesis of the extracellular matrix, will lead to myocardial fibrosis (Meekertetp et al., 2013).

In this study, the proliferation of cardiac fibroblasts cells was significant in the aldosterone group, and the cell density and number of cardiac fibroblasts were increased under a light microscope. The cell viability was decreased, and the number of cells was decreased in the middle and high dose groups of paeonol. Moreover, there was almost no difference in cell viability between the high-dose paeonol group and the positive control captopril group. This indicated that paeonol could inhibit the proliferation of cardiac fibroblasts cells.

Transforming growth factor beta (TGF $\beta$ ) is a large family of cytokines that primarily regulate cell growth and differentiation, causing fibrosis. TGF $\beta$ also regulates inflammatory responses and extracellular matrix deposition (Brandan et al., 2013). TGF $\beta$ is expressed in cardiac myocytes and cardiac fibroblasts. It plays an essential role in ventricular remodeling through two secretory modes, autocrine and paracrine. One classical mechanism by which TGF $\beta$ plays a role is the TGF $\beta$ binds to receptors on the cell surface, thereby activating the Smad pathway, the Smad-mediated signaling mechanisms. Besides, TGF $\beta$ activates extracellular signaling-related protein kinases, C-Jun amino-terminal kinase, p38 Schistogen-activated protein kinase (Derynck and Zhang, 2003).

There are four subtypes of TGF- $\beta$ in mammals, which are $\beta 1, \beta 2, \beta 3$, and $\beta 4$ in turn. As a crucial fibrogenic cytokine, TGF- $\beta_{1}$ can promote the proliferation of cardiac fibroblasts and the synthesis of type I and III collagen (Yang et al., 2013). TGF- $\beta_{1}$ can inhibit the synthesis of extracellular matrix-degrading enzymes, thus reducing the degradation of the extracellular matrix. TGF- $\beta_{1}$ can also promote the expression of many kinds of proteases, such as metalloproteinase inhibitor (Agrotis et al., 2014). TGF $\beta$ could promote the synthesis of collagen and accelerate the process of cellulose in diabetic cardiomyopathy (Asbun and
Villarreal, 2006).

Cardiac fibroblasts can synthesize and secrete collagen. Type I collagen and type III collagen is the main components of extracellular matrix, which in turn forms myocardial interstitium with fibroblasts, pericytes, and other fibrous connective tissues. In healthy adults, type I collagen accounts for about $80 \%-85 \%$ of myocardial collagen, while type III collagen accounts for only $11 \%$. Mature type I collagen mainly forms crude fibers, which can determine the heart's stiffness because of its less resilience, higher stiffness, and resistance to some degree of traction.

Immature type III collagen mainly forms fine fibers, which can reflect ventricular wall elasticity because of its strong extensibility. Both types I collagen and type III collagen are produced by fibroblasts. Their appropriate proportion plays a vital role in maintaining the integrity of normal myocardial tissue structure and cardiac function (Asbun and Villarreal, 2001).

Abnormal collagen metabolism is the main pathological basis of myocardial fibrogenesis (Cao et al., 2003). Changes in the ratio of type I collagen and type III collagen can reflect ventricular remodeling (Sun et al., 2000; Hanatani et al., 1998).

RT-PCR results showed that the expression of TGF- $\beta_{1}$ mRNA and type I collagen mRNA in the model group was significantly enhanced compared with the normal control group. The expression of TGF- $\beta_{1}$ mRNA and type I collagen mRNA decreased significantly after the intervention of middle and high doses of paeonol. The expression of TGF- $\beta_{1}$ mRNA and type I collagen mRNA was significantly decreased after positive control intervention.

Western blot results showed that the expression of type III collagen in the model group was significantly enhanced compared with the normal control group. However, the expression of type III collagen was significantly decreased after the intervention of paeonol. After the intervention of positive control, the expression of type III collagen was significantly decreased.

This shows that aldosterone can up-regulate the gene expression of TGF- $\beta_{1}$, type I collagen and type III collagen in cardiac fibroblasts. Brilla et al., (1994) suggested that aldosterone promotes collagen synthesis in cardiac fibroblasts, and the results of this study are consistent with Brilla's conclusion. However, after the addition of paeonol, paeonol can down-regulate the gene expression of TGF- $\beta_{1}$ type I collagen and type III collagen in cardiac fibroblasts, thereby improving ventricular remodeling. Paeonol can antagonize the effect of aldosterone on promoting collagen synthesis. Paeonol can reduce the synthesis of type I collagen and type III collagen, to antagonize and reverse ventricular 
remodeling. It is unclear whether paeonol inhibits collagen synthesis through a direct or indirect pathway. If it is achieved through an indirect pathway, whether a series of responses mediated through TGF- $\beta_{1}$ requires further investigation. This study will provide more basis for the development of paeonol as a new drug for anti-ventricular remodeling.

\section{Conclusion}

Paeonol can inhibit the proliferation and collagen synthesis of cardiac fibroblasts induced by aldosterone. Moreover, it is proved that paeonol has the effect of anti -aldosterone-induced ventricular remodeling at the cellular level. The molecular mechanism may be related to the down-regulation of type I collagen and type III collagen gene expression.

\section{Financial Support}

Hebei Provincial Administration of Traditional Chinese Medicine Project (Projects No.: 2018161), Hebei Provincial Health and Family Planning Commission (Projects No.: 20170875), and Chengde Medical University (Projects No.: 201612)

\section{Ethical Issue}

This study was approved by the Animal Ethics Committee of Chengde Medical University (No.: CDMULAC-20150716-003).

\section{Conflict of Interest}

Authors declare no conflict of interest

\section{References}

Agrotis A, Saltis J, Bobik A. Transforming growth factor- $\beta 1$ gene activation and growth of smooth muscle from hypertension rats. Hypertension 1994; 23: 593-99.

Asbun J, Villarreal FJ. The pathogenesis of myocardial fibrosis in the setting of diabetic cardiomyopathy. J Am Coll Cardiol. 2006; 47: 693-700.

Bahuguna A, Khan I, Bajpai VK, Kang SC. MTT assay to evaluate the cytotoxic potential of a drug. Bangladesh J Pharmacol. 2017, 12: 115-18.

Brandan E, Gutierrez J. Role of proteoglycans in the regulation of the skeletal muscle fibrotic response. FEBS J. 2013; 280: 4109-17.

Brilla CG, Zhou G, Matsubara L, Weber KT. Collagen metabolism in cultured adult rat cardiac fibroblasts: Response to angiotensin II and aldosterone. J Mol Cell Cardiol. 1994; 26: 809-20.

Cao Zheng, Wang Jianing, Yang Guiyuan, Li Jianjun. Aldos- terone promotes collagen synthesis by rat cardiac fibroblasts induced by angiotensin II. Chinese J Arterioscler. 2003; 11: 135-38.

Chen Y, Liu F, Han F, Lv L, Tang CE, Xie Z, Luo F. Omentin-1 is associated with atrial fibrillation in patients with cardiac valve disease. BMC Cardiovasc Disord. 2020; 20: 214.

Dartsch T, Fischer R, Gapelyuk A, Weiergraeber M, Ladage D, Schneider T, Schirdewan A, Reuter H, Mueller-Ehmsen J, Zobel C. Aldosterone induces electrical remodeling indepen -dent of hypertension. Int J Cardiol. 2013; 164: 170-78.

Derynck R, Zhang YE. Smad-dependent and Smad-independent pathways in TGF-beta family signalling. Nature 2003; 425: $577-84$

Gao Y, Zhang YM, Qian LJ, Chu M, Hong J, Xu D. ANO1 inhibits cardiac fibrosis after myocardial infraction via TGF$\beta$ /smad3 pathway. Sci Rep. 2017; 7: 2355.

Gu Yuanyuan, Zhou Xiaohui , Xu Qian, Zhao Jingyi. Effects of paeonol on RAS occurred on the development of ventricular remodeling after acute myocardial infarction in rats. Tianjin Med, 2015; 43: 470-73.

Han L, Tang Y, Li S, Wu Y, Chen X, Wu Q, Hong K, Li J. Protective mechanism of SIRT1 on Hcy-induced atrial fibrosis mediated by TRPC3. J Cell Mol Med. 2020; 24: 488510 .

Hanatani A, Yoshiyama M, Kim S, Omura T, Ikuno Y, Takeuchi K, Iwao H, Yoshikawa J. Assessment of cardiac function and gene expression at an early phase after myocardial infarction. Jpn Heart J. 1998; 39: 375-88.

Hayashi M, Tsutamoto T, Wada A, Maeda K, Mabuchi N, Tsutsui T, Matsui T, Fujii M, Matsumoto T, Yamamoto T, Horie H, Ohnishi M, Kinoshita M. Relationship between transcardiac extraction of aldosterone and left ventricular remodeling in patients with first acute myocardial infarction: Extracting aldosterone through the heart promotes ventricular remodeling after acute myocardial infarction. J Am Coll Cardiol. 2001; 38: 1375-82.

Hayashi M, Tsutamoto T, Wada A, Tsutsui T, Ishii C, Ohno K, Fujii M, Taniguchi A, Hamatani T, Nozato Y, Kataoka K, Morigami N, Ohnishi M, Kinoshita M, Horie M. Immediate administration of mineralocorticoid receptor antagonist spiro-nolactone prevents post-infarct left ventricular remodeling associated with suppression of a marker of myocardial collagen synthesis in patients with first anterior acute myocardial infarction. Circulation 2003; 107: 2559-65.

Lagarto JL, Dyer BT, Peters NS, French PMW, Dunsby C, Lyon AR. In vivo label-free optical monitoring of structural and metabolic remodeling of myocardium following infarction. Biomed Opt Express. 2019; 10: 3506-21.

Lee CY, Shin S, Lee J, Seo HH, Lim KH, Kim H, Choi JW, Kim SW, Lee S, Lim S, Hwang KC. MicroRNA-mediated downregulation of apoptosis signal-regulating kinase 1 (ASK1) attenuates the apoptosis of human mesenchymal stem cells (MSCs) transplanted into infarcted heart. Int J Mol Sci. 2016; 17: 1752.

Lieu FK, Lin CY, Wang PS, Jian CY, Yeh YH, Chen YA, Wang KL, Lin YC, Chang LL, Wang GJ, Wang SW. Effect of swimming on the production of aldosterone in rats. PLoS One. 2014; 9: e87080. 
Lu M, Qin Q, Yao J, Sun L, Qin X. Induction of LOX by TGF$\beta 1 / \mathrm{Smad} / \mathrm{AP}-1$ signaling aggravates rat myocardial fibrosis and heart failure. IUBMB Life. 2019; 71: 1729-39.

Meckert PC, Rivello HG, Vigliano C, González P, Favaloro R, Laguens R. Endomitosis and polyploidization of myocardial cells in the periphery of human acute myocardial infarction. Cardiovasc Res. 2005; 67: 116-23.

Prins KW, Thenappan T, Weir EK, Kalra R, Pritzker M, Archer SL. Repurposing medications for treatment of pulmonary arterial hypertension: What's old is new again. J Am Heart Assoc. 2019; 8: e011343.

Rossi G, Boscaro M, Ronconi V, Funder JW. Aldosterone as a cardiovascular risk factor. Trends Endocrinol Metab. 2005; 16: 104-07.

Schmidt K, Tissier R, Ghaleh B, Drogies T, Felix SB, Krieg T. Cardioprotective effects of mineralocorticoid receptor antago-nists at reperfusion. Eur Heart J. 2010; 31: 1655-62.

Shintani Y, Ito T, Fields L, Shiraishi M, Ichihara Y, Sato N, Podaru M, Kainuma S, Tanaka H, Suzuki K. IL-4 as a repurposed biological drug for myocardial infarction through augmentation of reparative cardiac macrophages: Proof-ofconcept data in mice. Sci Rep. 2017; 7: 6877.

Sun Y, Zhang JQ, Zhang J, Lamparter S. Cardiac remodeling by fibrous tissue after infarction in rats. J Lab Clin Med. 2000; 135: 316-23.

Sunaga $\mathrm{H}$, Koitabashi $\mathrm{N}$, Iso $\mathrm{T}$, Matsui $\mathrm{H}$, Obokata $\mathrm{M}$, Kawakami R, Murakami M, Yokoyama T, Kurabayashi M. Activation of cardiac AMPK-FGF21 feed-forward loop in acute myocardial infarction: Role of adrenergic overdrive and lipolysis byproducts. Sci Rep. 2019; 9: 11841.

Toldo S, Mezzaroma E, McGeough MD, Peña CA, Marchetti C, Sonnino C, Van Tassell BW, Salloum FN, Voelkel NF, Hoffman HM, Abbate A. Independent roles of the priming and the triggering of the NLRP3 inflammasome in the heart. Cardio-vasc Res. 2015; 105: 203-12.

Tsutamoto T, Wada A, Maeda K, Mabuchi N, Hayashi M, Tsutsui T, Ohnishi M, Sawaki M, Fujii M, Matsumoto T,
Matsui T, Kinoshita M. Effect of spironolactone on plasma brain natriuretic peptide and left ventricular remodeling in patients with congestive heart failure. J Am Coll Cardiol. 2001; 37: 1228-33.

Wang W. Effect of EPO on fibrosis of suckling mouse cardiac fibroblasts and the role of TGF-pi-TAKi-p38 MAPK in it. Kunming Medical University, 2013.

Wang Y, Chen J, Wang J, Guo X, Wang N, Yuan J. Antidepressant, neuropharmacological activity and mode of action of theaflavin-3-gallate in in vitro and in vivo models of depression. Bangladesh J Pharmacol. 2018; 13: 340-48.

Wilson EM, Spinale FG. Myocardial remodeling and matrix metallo proteinase in heart failure: Turmoil with in the interstitium. Ann Med. 2001; 33: 623-34.

Xu Q, Cao K, Xiao YH, Du C, Dong XH, Wang Y, Zhou XH. Effects of paeonol on the expression of NF-kB pathways in human umbilical veins endothelial cells induced by homocysteine. Bangladesh J Pharmacol. 2015; 10: 604-11.

Yang T, Zhang GF, Chen XF, Gu HH, Fu SZ, Xu HF, Feng Q, Ni YM. MicroRNA-214 provokes cardiac hypertrophy via repression of EZH2. Biochem Biophys Res Commun. 2013; 436: 578-84.

Zeng ZH, Luo BH, Gao YJ, Su CJ, He CC, Yi JJ, Li N, Lee RM. Control of vascular changes by renin-angiotensinaldosterone system in salt-sensitive hypertension. Eur J Pharmacol. 2004; 503: 129-33.

Zhang Y, Fan J. Overview of the study on cortex moutan IV overview of the pharmacological action of cortex moutan. Chongqing Chinese Herbal Med Res. 2009; 6: 24-31.

Zhao J, Dong H, Zhou X, Yao Y, Zhang S. Effects of paeonol on ventricular remodeling and expression of NF-kBp65 and IL$1 \mathrm{mRNA}$ in rats with acute myocardial infarction. Chinese J Exper Formulae. 2014; 20: 177-80.

Zhao J, Zhang S, Yao Y, Gu Y, Shi Z, Zhou X. Effects of paeonol on nuclear factor-kB p65 pathway after acute myocardial infarction in rats. Chinese J Gerontol. 2017; 37: 22-24.

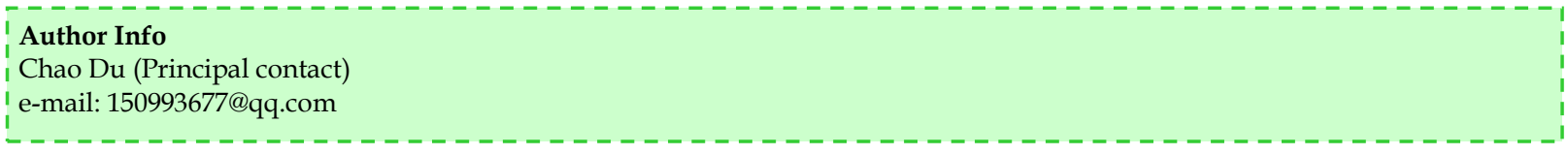

